\title{
Multidimensional Analysis of 16 Glucose Isomers by lon Mobility Spectrometry
}

M. M. Gaye, ${ }^{1^{\star}}$ G. Nagy, ${ }^{1}$ D. E. Clemmer ${ }^{1}$ and N. L. B. Pohl, ${ }^{1}$

${ }^{1}$ Department of Chemistry, Indiana University, Bloomington, IN 47405

*To whom the correspondence should be addressed. E-mail: mgaye@indiana.edu

\section{Supporting Information}

\section{1- Experimental section}

IMS-MS measurements. Ions are produced by $\mathrm{ESI}^{1}$ and introduced to the two meter long drift tube using an automatic injection system (NanoMate TriVersa, Advion, Ithaca, NY). After accumulation in the hour-glass source funnel ${ }^{2,3}$, ions are periodically pulsed into the drift tube as a $150 \mu$ s wide packet of ions. In the present experiment, the drift tube is filled with $\sim 2.28$ to 3 Torr of $\mathrm{He}$ at $294 \mathrm{~K}$ and operated under a uniform electric field of $9.6 \mathrm{~V} \cdot \mathrm{cm}^{-1}$. Under these conditions, ions are separated according to their mobilities in He buffer gas prior to extraction into the TOF detector for mass analysis. Because the mobility separation takes place in a millisecond time-scale and the MS analysis in a microsecond time-scale, a nested measurement of the time it takes ions to travel through the drift tube (drift time, $t_{D}$ ) as a function of $\mathrm{m} / \mathrm{z}$ is obtained. The instrument being operated in the low-field regime, collision cross sections are derived from the direct measurement of $t_{D}$ using the following equations ${ }^{4,5}$ :

$$
K_{0}=\frac{L^{2}}{t_{D} V} \times \frac{273.2}{T} \times \frac{P}{760}
$$




$$
\Omega=\frac{(18 \pi)^{1 / 2}}{16} \frac{z e}{\left(k_{B} T\right)^{1 / 2}}\left[\frac{1}{m_{I}}+\frac{1}{m_{B}}\right]^{1 / 2} \frac{1}{K_{0}} \frac{1}{N}
$$

The reduced mobility $\left(K_{0}\right)$ depends on $t_{D}$, the instrument length $(L)$, the voltage applied across the drift tube $(V)$, the pressure $(P)$ and the temperature $(T)$ of the buffer gas (1). Finally, knowing $K_{0}$, the ion charge state $(z)$, masses of the ion and buffer gas $\left(m_{1}\right.$ and $m_{B}$ respectively), Boltzmann's constant $\left(k_{B}\right)$ and the number density of the buffer gas at $\operatorname{STP}(N)$, the $\operatorname{ccs}(\Omega)$ is calculated $(2)$.

Data analysis. Origin ${ }^{\circledR} 9$ software (Northampton, MA) is used for the principal component analysis as well as for the peak width and full width at half maximum calculations.

\section{Supplementary tables and figures}

$\begin{array}{lccc}\text { collision cross section }\left(\AA^{2}\right) & \\ \text { monosaccharide } & \left.\begin{array}{c}\text { ch-Ser }+\mathrm{M}+\mathrm{H}]^{+} \\ {[\mathrm{L}-\mathrm{Phe}-\mathrm{Gly}+\mathrm{M}+\mathrm{H}]^{+}}\end{array} \mathrm{Mn}^{\|}+(\mathrm{L}-\mathrm{Phe}-\mathrm{Gly}-\mathrm{H})+\mathrm{M}\right]^{+} \\ \text {D-glucose } & 99.4 \pm 0.4 & 129.7 \pm 0.1 & 119.4 \pm 0.2 \\ \text { D-mannose } & 95.3 \pm 0.6 & 125.4 \pm 0.2 & 122.8 \pm 0.3 \\ \text { D-altrose } & 93.8 \pm 0.5 & 122.9 \pm 0.6 & 120.2 \pm 0.4 \\ \text { D-idose } & 94.7 \pm 0.3 & 123.0 \pm 0.4 & 120.9 \pm 0.8 \\ \text { D-galactose } & 96.2 \pm 0.5 & 127.3 \pm 1.5 & 120.6 \pm 0.1 \\ \text { D-allose } & 97.5 \pm 1.0 & 129.5 \pm 0.2 & 120.0 \pm 0.1 \\ \text { D-talose } & 94.0 \pm 0.7 & 124.1 \pm 0.3 & 120.9 \pm 0.4 \\ \text { D-gulose } & 96.3 \pm 0.4 & 125.4 \pm 0.2 & 128.0 \pm 0.5 \\ \text { L-glucose } & 99.5 \pm 0.2 & 130.2 \pm 0.9 & 121.2 \pm 0.3 \\ \text { L-mannose } & 95.1 \pm 0.7 & 125.8 \pm 0.3 & 119.1 \pm n a \\ \text { L-altrose } & 94.3 \pm 0.5 & 125.6 \pm 0.2 & 120.5 \pm 0.4 \\ \text { L-idose } & 94.3 \pm 0.3 & 125.3 \pm 0.2 & 121.4 \pm 0.6 \\ \text { L-galactose } & 96.9 \pm 0.4 & 127.0 \pm 0.1 & 124.2 \pm 1.0 \\ \text { L-allose } & 97.9 \pm 0.7 & 129.3 \pm 0.2 & 121.9 \pm 0.5 \\ \text { L-talose } & 94.4 \pm 0.4 & 126.7 \pm 0.6 & 122.2 \pm 0.7 \\ \text { L-gulose } & 96.6 \pm 0.4 & 127.5 \pm 0.7 & 125.3 \pm 1.0\end{array}$

Table S-1: Collision cross sections of cluster ions a measured in He buffer gas by IMS-MS for 16 glucose isomers. a In each cluster ion, $M$ represents a given monosaccharide. Average collision cross sections are obtained from triplicate measurements at the exception of $\left[\mathrm{Mn}^{\|+}+(\mathrm{L}-\mathrm{Phe}-\mathrm{Gly}-\mathrm{H})+\mathrm{M}\right]^{+}$cluster ions formed with $\mathrm{D}$-idose, D-galactose (duplicate measurements) and L-mannose (single measurement). 

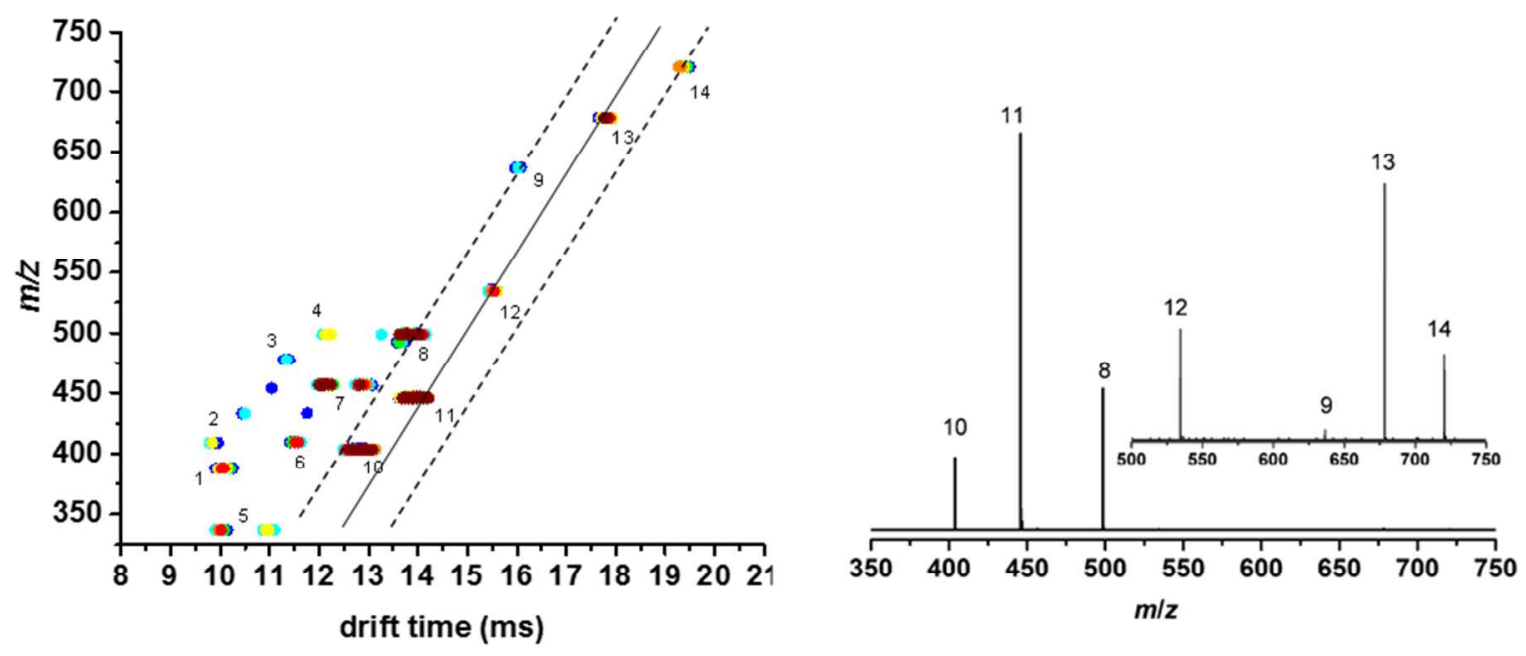

Figure S-1: The signal along the solid diagonal line overlaid on the nested $t_{D}(\mathrm{~m} / \mathrm{z})$ spectrum (2Dplot) shown in Figure 1A is integrated (left panel). The dash lines indicate the upper and lower limits of integration respectively (left panel). The resulting mass spectrum is shown on the right panel. Ion labels are identical to the ones used in the manuscript (Figure 1A and Table 1). 

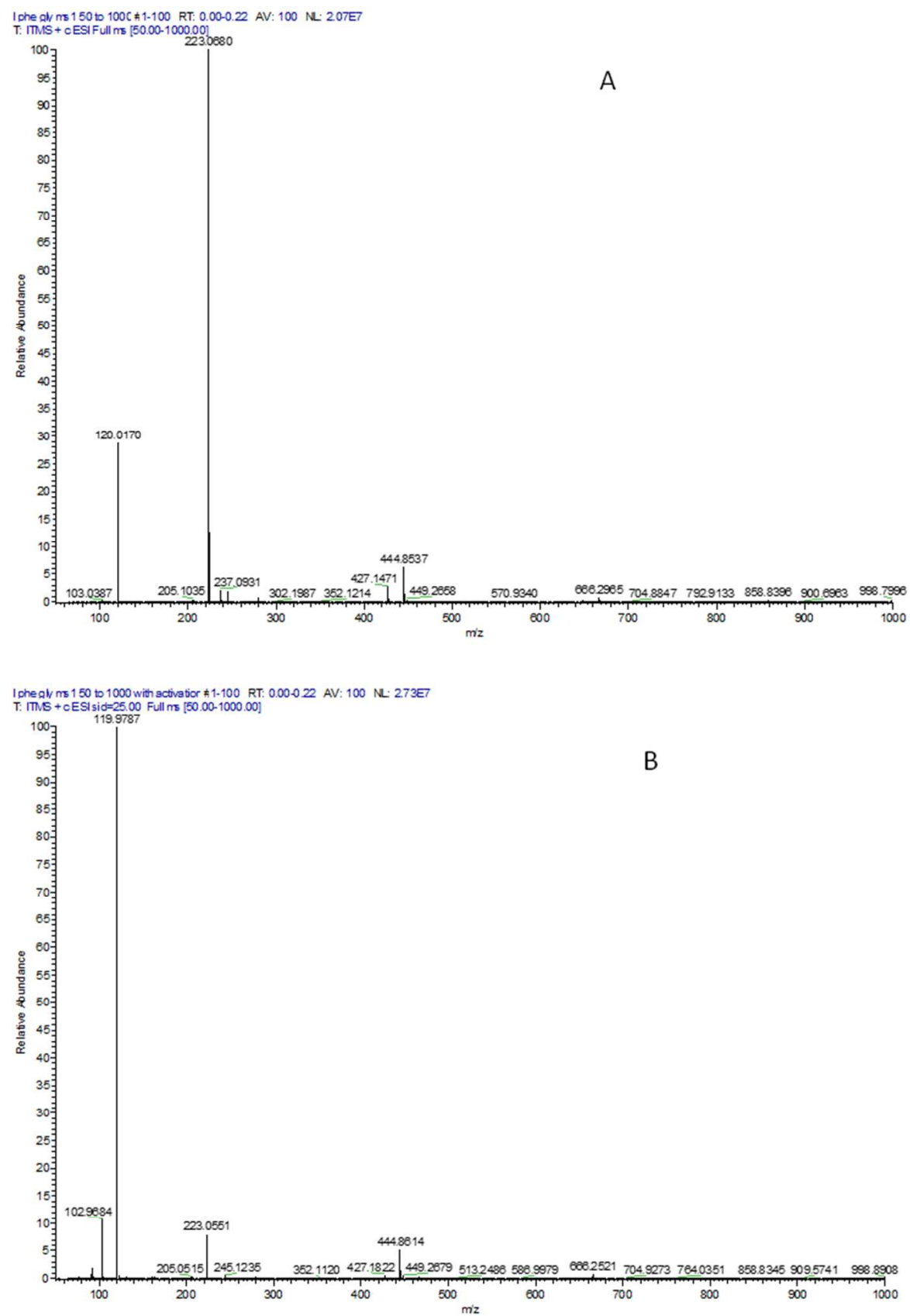

Figure S-2: Mass spectrum without activation for the peptide L-Phe-Gly used in this study (A). The ion [L-Phe-Gly+H] ${ }^{+}$is at $223 \mathrm{~m} / \mathrm{z}$. The ion at $103 \mathrm{~m} / \mathrm{z}$ corresponds to the fragment $\mathrm{X}_{1}$ reported in complex ion 5 (Table 1). The ion at $120 \mathrm{~m} / z$ corresponds to the fragment $a_{1}$ reported in complex ion 12 (Table 1). The mass spectrum obtained upon activation (B) confirms that the ions at $103 \mathrm{~m} / \mathrm{z}$ and $120 \mathrm{~m} / \mathrm{z}$ are fragment ions 

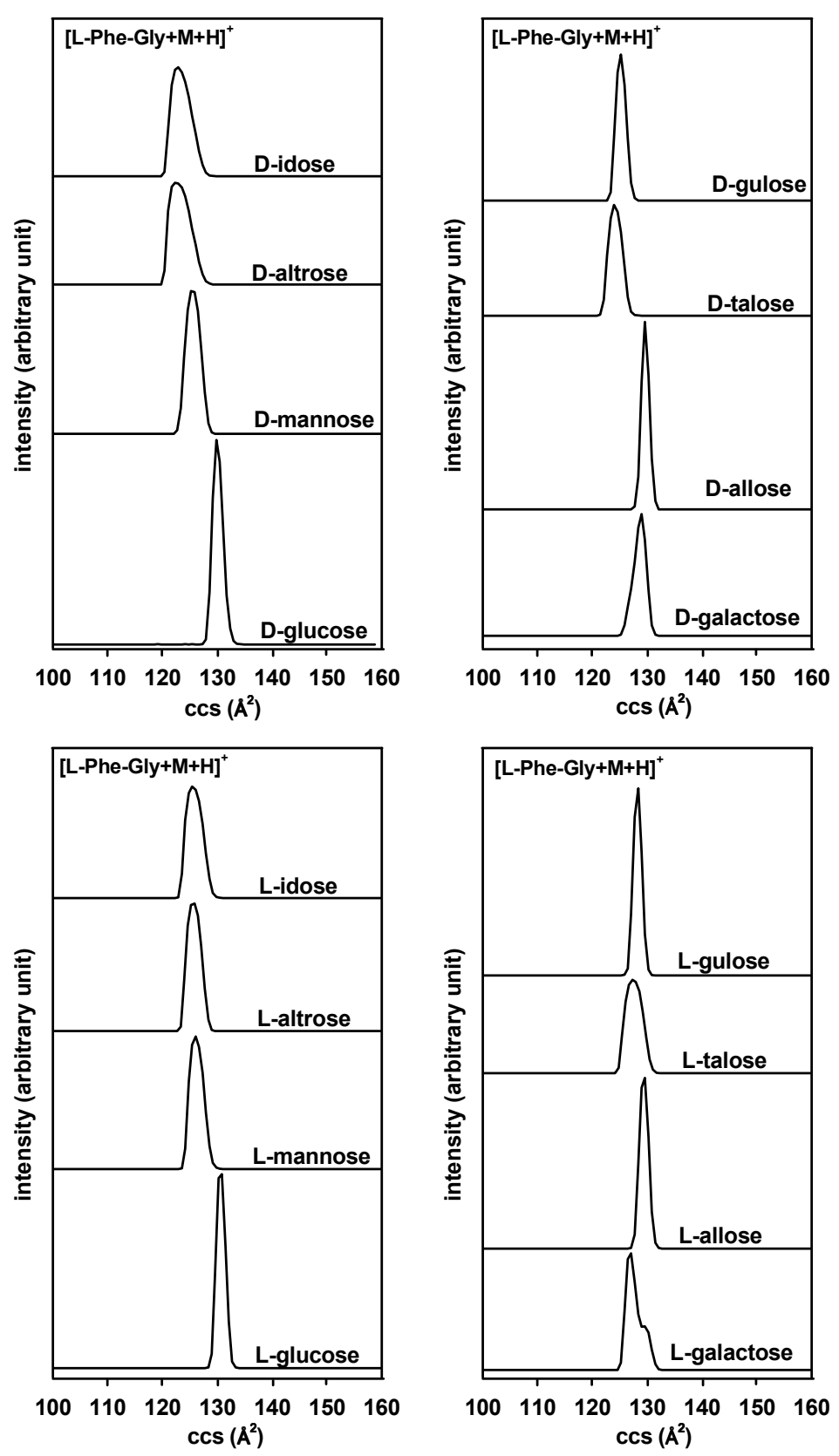

Figure S-3: Mobility distributions on a collision cross section scale (ccs in $\left.\AA^{2}\right)$ of the singly-charged protonated dimeric complex [L-Phe-Gly+M+H] ${ }^{+}(\mathrm{m} / \mathrm{z} 403)$, where $\mathrm{M}$ is a given monosaccharide, for the 16 monosaccharides represented in Scheme 1. The top two panels correspond to the Denantiomers and the bottom two panels correspond to the L-enantiomers. The monosaccharide name is indicated as an insert and ccs values are reported in Table S-1. 

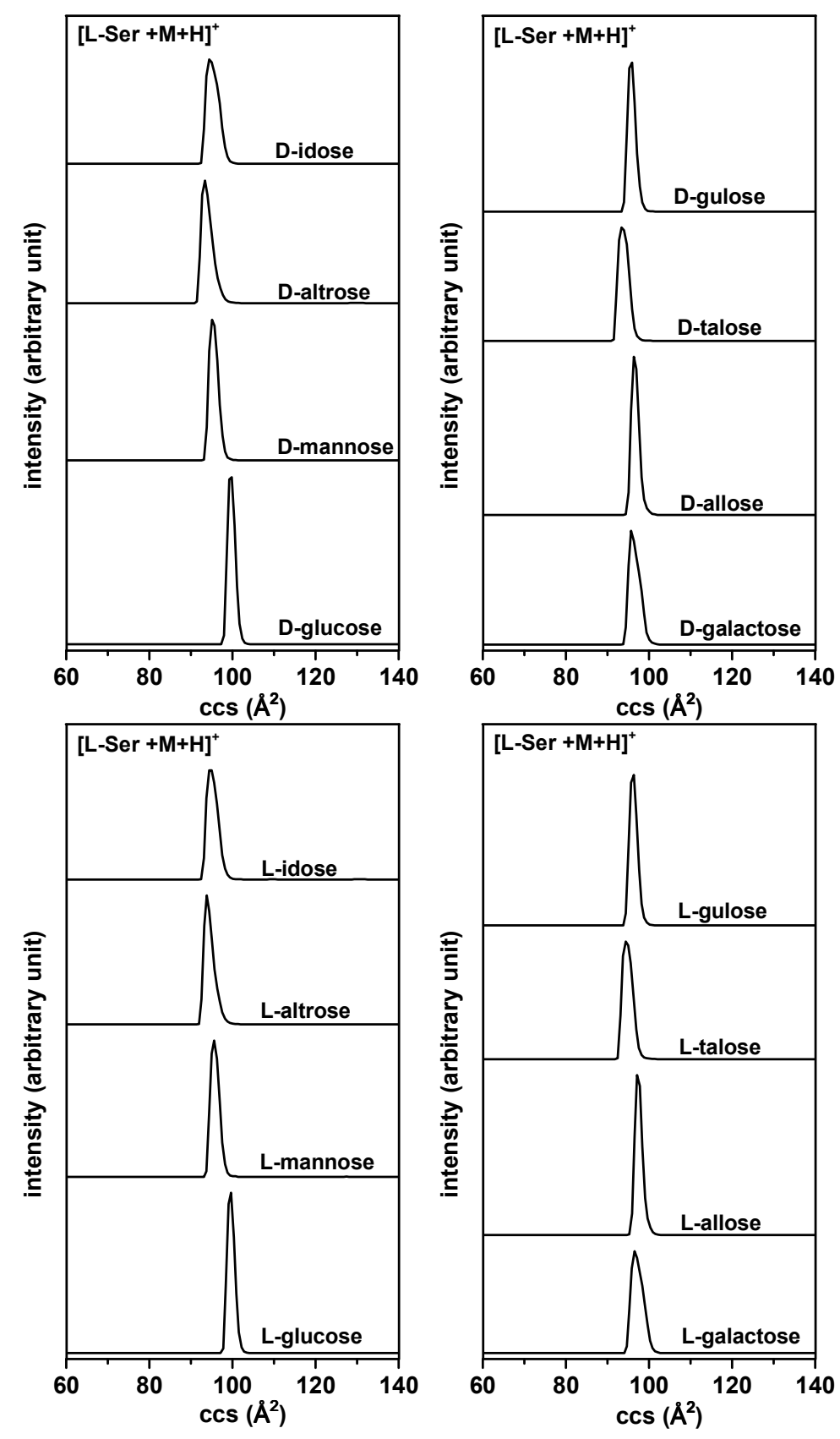

Figure S-4: Mobility distributions of the dimeric complex [L-Ser+M+H] ${ }^{+}(\mathrm{m} / \mathrm{z} 286)$ where $\mathrm{M}$ is a given monosaccharide. Collision cross sections associated with the 16 monosaccharides represented in Scheme 1 are reported in Table S-1. D-enantiomers and L-enantiomers are depicted in the top and bottom panels respectively. 


\begin{tabular}{lcccc}
\multicolumn{5}{c}{ collision cross section $\left(\AA^{2}\right)$} \\
monosaccharide & {$\left[\mathrm{Co}^{\prime \prime}+(\mathrm{L}-\mathrm{Ser}-\mathrm{H})+\mathrm{M}\right]^{+}$} & {$\left[\mathrm{Co}^{\|}+(\mathrm{L}-\mathrm{Asn}-\mathrm{H})+\mathrm{M}\right]^{+}$} & {$\left[\mathrm{Mn}{ }^{\| \prime}+(\mathrm{L}-\mathrm{Ser}-\mathrm{H})+\mathrm{M}\right]^{+}$} & {$\left[\mathrm{Mn}{ }^{\|+}+(\mathrm{L}-\mathrm{Asn}-\mathrm{H})+\mathrm{M}\right]^{+}$} \\
D-idose & $94.5 \pm 0.9$ & $101.4 \pm 0.1$ & $96.2 \pm 0.6$ & $101.8 \pm 1.4$ \\
L-idose & $94.7 \pm 0.3$ & $101.5 \pm 0.3$ & $96.1 \pm 0.8$ & $102.3 \pm 0.6$ \\
D-talose & $97.1 \pm 0.8$ & $102.7 \pm 0.8$ & $95.8 \pm 0.9$ & $101.3 \pm 0.8$ \\
D-altrose & $94.8 \pm 0.6$ & $102.9 \pm 0.2$ & $96.2 \pm 0.7$ & $103.2 \pm 0.9$
\end{tabular}

Table S-2: Collision cross sections of the cluster ions used in the evaluation of different combinations of amino acid, peptide and metal ions (triplicate measurements, Figure 4. A).

\begin{tabular}{lcccc} 
& \multicolumn{3}{c}{ collision cross section $\left(\AA^{2}\right)$} \\
monosaccharide & {$[\mathrm{L}-\mathrm{Tyr}-\mathrm{Gly}+\mathrm{M}]^{+}$} & $[\mathrm{L}-\mathrm{Trp}-\mathrm{Gly})+\mathrm{M}]^{+}$ & {$[\mathrm{L}-\mathrm{P}+\mathrm{M}]^{+}$} & {$\left[\mathrm{Mn}{ }^{\prime \prime}+(\mathrm{L}-\mathrm{Asn}-\mathrm{H})+\mathrm{M}\right]^{+}$} \\
D-idose & $94.5 \pm 0.9$ & $101.4 \pm 0.1$ & $96.2 \pm 0.6$ & $101.8 \pm 1.4$ \\
L-idose & $94.7 \pm 0.3$ & $101.5 \pm 0.3$ & $96.1 \pm 0.8$ & $102.3 \pm 0.6$
\end{tabular}

Table S-3: Collision cross sections of the cluster ions used in the evaluation of different combinations of peptide with D- and L-idose (triplicate measurements, Figure 4. B). 


\begin{tabular}{|c|c|c|c|c|}
\hline \multirow[b]{2}{*}{ Cluster Ion } & \multicolumn{4}{|c|}{ collision cross section $\left(\AA^{2}\right)$} \\
\hline & D-altrose & D-idose & D-talose & L-idose \\
\hline$[\mathrm{L}-\mathrm{Ser}+\mathrm{M}+\mathrm{H}]^{+}$ & $93.8 \pm 0.5$ & $94.7 \pm 0.3$ & $94.0 \pm 0.7$ & $94.3 \pm 0.3$ \\
\hline$\left[\mathrm{Mn}^{\prime \prime}+(\mathrm{L}-\mathrm{Ser}-\mathrm{H})+\mathrm{M}\right]^{+}$ & $96.2 \pm 0.7$ & $96.2 \pm 0.6$ & $95.8 \pm 0.9$ & $96.1 \pm 0.8$ \\
\hline$\left[\mathrm{Co}^{\prime \prime}+(\mathrm{L}-\mathrm{Ser}-\mathrm{H})+\mathrm{M}\right]^{+}$ & $94.8 \pm 0.6$ & $94.5 \pm 0.9$ & $97.1 \pm 0.8$ & $94.7 \pm 0.3$ \\
\hline$\left[\mathrm{Mn}^{\prime \prime}+(\mathrm{L}-\mathrm{Pro}-\mathrm{H})+\mathrm{M}\right]^{+}$ & $83.2 \pm 1.0$ & $83.1 \pm 0.7$ & $82.8 \pm 1.0$ & $83.3 \pm 1.1$ \\
\hline$\left[\mathrm{Mn}^{\prime \prime}+(\mathrm{L}-\mathrm{Asn}-\mathrm{H})+\mathrm{M}\right]^{+}$ & $103.2 \pm 0.9$ & $101.7 \pm 1.4$ & $101.3 \pm 0.8$ & $102.3 \pm 0.6$ \\
\hline$\left[\mathrm{Co}^{\prime \prime}+(\mathrm{L}-\mathrm{Asn}-\mathrm{H})+\mathrm{M}\right]^{+}$ & $102.9 \pm 0.2$ & $101.4 \pm 0.1$ & $102.7 \pm 0.8$ & $101.5 \pm 0.3$ \\
\hline$[\mathrm{Co}+(\mathrm{L}-\mathrm{G} \ln -\mathrm{H})+\mathrm{M}]^{+}$ & $105.4 \pm 1.1$ & $105.1 \pm 0.3$ & $106.8 \pm 1.3$ & $105.4 \pm 0.1$ \\
\hline$[\text { L-Phe-Gly +M+H }]^{+}$ & $122.9 \pm 0.6$ & $123.0 \pm 0.4$ & $124.1 \pm 0.3$ & $125.3 \pm 0.2$ \\
\hline$\left[\mathrm{Mn}^{\prime \prime}+(\mathrm{L}-\mathrm{Phe}-\mathrm{Gly}-\mathrm{H})+\mathrm{M}\right]^{+}$ & $120.2 \pm 0.4$ & $120.9 \pm 0.8$ & $120.9 \pm 0.4$ & $121.4 \pm 0.6$ \\
\hline$\left[\mathrm{Co}^{\prime \prime}+(\mathrm{L}-\text { Pro-H)+L-Pro+M }]^{+}\right.$ & $124.7 \pm 0.8$ & $125.6 \pm 1.4$ & $126.4 \pm 1.1$ & $126.4 \pm 1.2$ \\
\hline
\end{tabular}

Table S-4: Collision cross sections of cluster ions used in the principal component analysis. The two principal components are represented in Figure S-3 for D-altrose, D- and L-idose and D-talose. All measurements are realized in triplicate at the exception of [Co"l $+(\mathrm{L}-\mathrm{G} \mathrm{In}-$ $\mathrm{H})+\mathrm{M}]^{+}$and $\left[\mathrm{Co}^{\|+}+(\mathrm{L}-\text { Pro-H })+\mathrm{L}-\mathrm{PrO}+\mathrm{M}\right]^{+}$(duplicate measurements). 


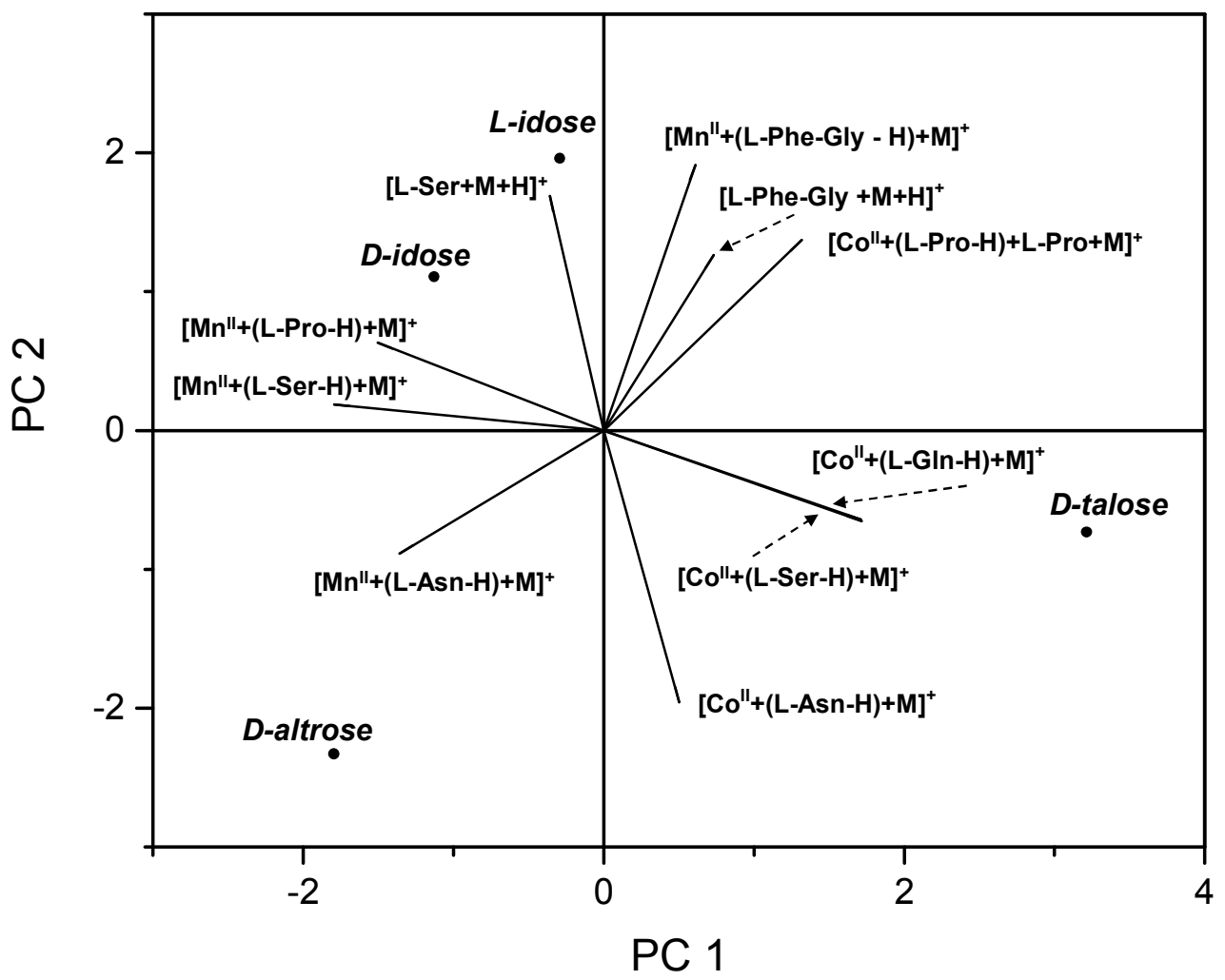

Figure S-5 Representation of the two first principal components for D-altrose, D- and Lidose and D-talose overlaid with the extracted eigenvectors for the 10 cluster ions subjected to the principal component analysis and listed in Table S-4. 
(A)

\begin{tabular}{cccc|} 
& Eigenvalue & Percentage of Variance & Cumulative \\
\hline 1 & 4.96727 & $49.7 \%$ & $49.7 \%$ \\
2 & 3.67739 & $36.8 \%$ & $86.5 \%$ \\
3 & 1.35534 & $13.6 \%$ & $100.0 \%$ \\
4 & 0 & $0.0 \%$ & $100.0 \%$ \\
5 & 0 & $0.0 \%$ & $100.0 \%$ \\
6 & 0 & $0.0 \%$ & $100.0 \%$ \\
7 & 0 & $0.0 \%$ & $100.0 \%$ \\
8 & 0 & $0.0 \%$ & $100.0 \%$ \\
9 & 0 & $0.0 \%$ & $100.0 \%$ \\
10 & 0 & $0.0 \%$ & $100.0 \%$ \\
\hline
\end{tabular}

(B)

$\begin{array}{lccc} & \text { Coefficients of PC1 } & \text { Coefficients of PC2 } & \text { Coefficients of PC3 } \\ \text { [L-Ser+M+H]+ } & -0.0889 & 0.42332 & -0.47185 \\ \text { [Mnll+(L-Ser-H)+M]+ } & -0.44534 & 0.04689 & -0.07056 \\ \text { [Coll+(L-Ser-H)+M]+ } & 0.42572 & -0.1643 & -0.01913 \\ \text { [Mnll+(L-Pro-H)+M]+ } & -0.37331 & 0.15893 & 0.39817 \\ \text { [Mnll+(L-Asn-H)+M]+ } & -0.33714 & -0.22252 & 0.43232 \\ \text { [Coll+(L-Asn-H)+M]+ } & 0.12471 & -0.49151 & 0.15923 \\ \text { [Coll+(L-Gln-H)+M]+ } & 0.42534 & -0.16154 & 0.063 \\ \text { [L-Phe-Gly+M+H]+ } & 0.18176 & 0.31692 & 0.5867 \\ \text { [Mnll+(L-Phe-Gly - H)+M]+ } & 0.15094 & 0.47971 & 0.17301 \\ \text { [Coll+(L-Pro-H)+L-Pro+M]+ } & 0.32744 & 0.34438 & 0.15195\end{array}$

Table S-5: (A) Eigenvalues of the correlation matrix for the principal component analysis performed on the 10 cluster ions listed in Table S-4. (B) Extracted eigenvectors for the 10 cluster ions listed in Table S-4 and represented in Figure S-5. 


\begin{tabular}{|c|c|c|c|c|c|c|c|c|c|c|c|c|c|c|c|}
\hline & \multicolumn{5}{|c|}{ [L-Ser+M+H]* } & \multicolumn{5}{|c|}{ [L-Phe-Gly+M+H]* } & \multicolumn{5}{|c|}{$\left[M^{\prime \prime}+(\right.$ L-Phe-Gly - H)+M]* } \\
\hline & $\operatorname{ccs}\left(\AA^{2}\right)$ & FWHM $^{*}$ & $\mathbf{R}_{\mathrm{p}}$ & $\mathbf{W}_{\mathrm{b}}{ }^{\mathrm{a}}$ & FWHM $^{\mathrm{b}}$ & $\operatorname{ccs}\left(\AA^{2}\right)$ & FWHM $^{3}$ & $\mathbf{R}_{\mathrm{p}}$ & $W_{b}{ }^{a}$ & FWHM $^{\mathrm{D}}$ & $\operatorname{ccs}\left(\AA^{2}\right)$ & FWHM $^{3}$ & $\mathbf{R}_{p}$ & $\mathbf{W}_{\mathrm{D}}{ }^{\mathrm{a}}$ & FWHM $^{\mathrm{D}}$ \\
\hline D-glucose & 99.4 & 2.2 & 44.5 & 6.3 & 0.20 & 129.7 & 2.3 & 55.6 & 6.3 & 0.21 & 119.4 & 1.4 & 82.9 & 5.0 & 0.12 \\
\hline D-mannose & 95.3 & 2.6 & 36.1 & 7.6 & 0.23 & 125.4 & 3.4 & 36.7 & 7.5 & 0.30 & 122.8 & 1.5 & 82.6 & 6.9 & 0.13 \\
\hline D-altrose & 93.8 & 2.9 & 31.9 & 9.4 & 0.20 & 122.9 & 4.8 & 25.5 & 9.4 & 0.42 & 120.2 & 1.3 & 92.1 & 5.0 & 0.12 \\
\hline D-idose & 94.7 & 3.8 & 24.8 & 8.9 & 0.34 & 123.0 & 4.5 & 27.3 & 8.8 & 0.40 & 120.9 & 2.2 & 55.4 & 6.3 & 0.21 \\
\hline D-galactose & 96.2 & 3.2 & 29.7 & 8.7 & 0.30 & 127.3 & 2.6 & 48.7 & 8.2 & 0.25 & 120.6 & 1.6 & 73.1 & 5.0 & 0.15 \\
\hline D-allose & 97.5 & 2.2 & 44.4 & 7.6 & 0.20 & 129.5 & 1.8 & 72.7 & 5.0 & 0.16 & 120.0 & 0.9 & 127.2 & 3.8 & 0.09 \\
\hline D-talose & 94.0 & 3.2 & 29.5 & 7.5 & 0.28 & 124.1 & 3.1 & 40.0 & 7.5 & 0.27 & 120.9 & 2.2 & 55.2 & 5.6 & 0.19 \\
\hline D-gulose & 96.3 & 2.3 & 41.0 & 6.9 & 0.21 & 125.4 & 2.3 & 55.0 & 5.0 & 0.21 & 128.0 & 1.7 & 73.2 & 5.0 & 0.16 \\
\hline L-glucose & 99.5 & 2.2 & 45.5 & 5.7 & 0.20 & 130.2 & 2.1 & 63.1 & 5.0 & 0.18 & 121.2 & 1.2 & 99.0 & 4.4 & 0.12 \\
\hline L-mannose & 95.1 & 2.6 & 36.3 & 7.0 & 0.23 & 125.8 & 3.2 & 39.5 & 6.9 & 0.28 & 119.1 & 1.5 & 81.4 & 6.3 & 0.12 \\
\hline L-altrose & 94.3 & 2.6 & 36.6 & 8.7 & 0.24 & 125.6 & 3.3 & 38.2 & 2.9 & 0.29 & 120.5 & 1.4 & 84.6 & 5.0 & 0.13 \\
\hline L-idose & 94.3 & 3.3 & 28.5 & 8.3 & 0.29 & 125.3 & 3.8 & 33.0 & 8.2 & 0.33 & 121.4 & 2.0 & 60.1 & 5.0 & 0.18 \\
\hline L-galactose & 96.9 & 3.5 & 27.5 & 8.7 & 0.33 & 127.0 & 2.5 & 51.7 & 7.5 & 0.25 & 124.2 & 1.9 & 65.5 & 5.0 & 0.17 \\
\hline L-allose & 97.9 & 2.1 & 45.7 & 6.9 & 0.19 & 129.3 & 2.1 & 61.6 & 5.6 & 0.19 & 121.9 & 1.5 & 79.6 & 3.8 & 0.14 \\
\hline L-talose & 94.4 & 3.1 & 30.5 & 7.6 & 0.27 & 126.7 & 4.0 & 31.9 & 7.5 & 0.34 & 122.2 & 2.3 & 53.3 & 5.0 & 0.20 \\
\hline L-gulose & 96.6 & 2.3 & 41.2 & 7.6 & 0.21 & 127.5 & 1.9 & 66.9 & 5.0 & 0.17 & 125.3 & 1.5 & 81.8 & 4.8 & 0.13 \\
\hline
\end{tabular}

Table S-6 Collision cross sections (ccs), full width at half maximum (FWHM), resolving power (Rp) and width at the base $\left(W_{b}\right)$ associated with the ion mobility peaks of [L-Ser+M+H] $]^{+}$, [L-Phe-Gly+M+H] ${ }^{+}$and $\left[\mathrm{Mn}{ }^{\| \prime}+(\mathrm{L}-\mathrm{Phe}-\mathrm{Gly}-\mathrm{H})+\mathrm{M}\right]^{+}$ cluster ions used in the three-dimensional representation of the dataset (Figure 3 ) for 16 glucose isomers.

a FWHM and $\mathrm{W}_{\mathrm{b}}$ measured in the ccs dimension.

${ }^{b}$ FWHM measured in the drift time dimension.

\section{References}

(1) Fenn, J. B.; Mann, M.; Meng, C. K.; Wong, S. F.; Whitehouse, C. M. Mass Spectrometry Reviews. 1990, 9, 37-70.

(2) Shaffer, S. A.; Prior, D. C.; Anderson, G. A.; Udseth, H. R.; Smith, R. D. Anal. Chem. 1998, 70, 4111-4119.

(3) Tang, K.; Shvartsburg, A. A.; Lee, H.; Prior, D. C.; Buschbach, M. A.; Li, F.; Tomachev, A.; Anderson, G. A.; Smith, R. D. Anal. Chem. 2005, 77, 3330-3339.

(4) Clemmer, D. E.; Jarrold, M. F. J. Mass Spectrom. 1997, 32, 577-592.

(5) Revercomb, H. E.; Mason, E. A. Anal. Chem. 1975, 47, 970-983. 